\title{
Driving change: Exploring the adoption of multimodal local traffic impact assessment practices
}

\author{
Tabitha S. Combs \\ University of North Carolina \\ tab@unc.edu
}

\author{
Noreen C. McDonald \\ University of North Carolina \\ noreen@unc.edu
}

\begin{abstract}
Local governments are increasingly recognizing the need to improve multimodal mobility. Using interviews with officials in 36 eastern US communities, we explore factors influencing the adoption of new traffic-impact-assessment (TIA) practices that support multimodal objectives. We focus on communities' motivations and supports for multimodal-oriented practices, as well as challenges they face in adopting these practices. By examining both the prevalence of multimodalsupportive TIA practices adopted by our study communities and the motivations for and challenges to adopting these practices, we identify pathways through which transportation researchers can better support communities' efforts to more closely align their TIA practices with desired multimodal-supportive outcomes.
\end{abstract}

\author{
Article history: \\ Received: February 4, 2020 \\ Received in revised form: \\ June 29, 2020 \\ Accepted: August 8, 2020 \\ Available online: January 5, \\ 2021
}

\section{Introduction}

Local governments in the US face growing public demands to reduce automobile dependence in order to forestall climate change, improve road safety, rein in sprawling peripheral land development, increase transportation equity, and enhance urban livability. As a result, many city and county leaders are looking for ways to provide alternatives to driving through the creation of more multimodal-supportive transportation systems and land use patterns. The academic literature has identified conventional traffic-impact-assessment (TIA) practices-designed to ensure new developments do not increase automobile traffic congestion — as a barrier to supporting these multimodal efforts. Because of the growing emphasis on multimodality in many national, state, and regional policies and initiatives (e.g., Complete Streets, Vision Zero), we investigate whether and how communities were adapting TIA practices to better accommodate pedestrians, bicyclists, transit users, and other non-car travel modes in the land development process.

Many cities and counties in the US are attempting to adapt their practices for evaluating and mitigating the impacts of development to bring them more in line with multimodal-oriented objectives, with widely varying degrees of success (Combs, McDonald, \& Leimenstoll, 2020). Much of the research on multimodal-oriented TIA practices in the US has focused on California, where state-level mandates have led to practice changes at the state and local levels (Currans, 2017; Governor's Office of Planning and Research, 2019). Our goals in this study are to identify such multimodal TIA adaptations in use in cities and counties in other areas of the country. We focus on cities in the three US states (Maryland, North Carolina, and Virginia), and seek to identify and describe multimodal TIA adapta-

Copyright 2021 Tabitha S. Combs \& Noreen C. McDonald

http://dx.doi.org/10.5198/jtlu.2021.1730

ISSN: 1938-7849 | Licensed under the Creative Commons Attribution - Noncommercial License 4.0

The Journal of Transport and Land Use is the official journal of the World Society for Transport and Land Use (WSTLUR) and is published and sponsored by the University of Minnesota Center for Transportation Studies. 
tions taking place there, as well as the drivers and barriers to change and sources to which local governments turn for information about multimodal TIA practices.

Our research indicates that many communities in our study area are indeed making efforts to adapt their TIA practices to incorporate and/or accommodate more multimodal objectives. Based on a combination of motivation for moving to a more multimodal practice, and success in adapting TIA to support multimodal objectives, we identify five types of communities: leading, following, aspiring, lagging, and conventional. Our findings suggest that leading communities are adopting a wide range of alternative practices, and, despite strong similarities in motivations for changing practices, the practices adopted practices vary greatly across leading communities. We posit that this apparent divergence in practices may reflect both a lack of consensus regarding best practices for multimodal TIA and a recognition of the importance of context-sensitive approaches to TIA. The research also identifies factors associated with the change process that may help explain differences in the uptake of alternative practices across our sample.

\section{$2 \quad$ Background}

Traffic impact assessment (TIA; also known as traffic impact analysis or traffic impact statement) is a means for estimating the amount of new traffic that is likely to be induced by a development project. The conventional approach to TIA assumes that the increased traffic will be in the form of motor vehicle trips. If those new trips impose a "cost" on the existing transportation system, the thinking goes, the burden of mitigating those costs should be passed on to developers who "cause" the increased traffic.

Historically, the primary metrics used to determine whether and to what extent mitigations are required are focused on motor vehicles: specifically, vehicle trip generation and vehicle level of service (LOS, a rating system focused on the convenience and flow of motor vehicles). In the conventional TIA model, engineers estimate the number of new vehicle trips a project will produce based on The Institute of Traffic Engineers (ITE) coefficients, which are available from ITE's trip generation manual (ITE has published this manual regularly; the most recent edition, the 10th, was published in 2017; Institute of Transportation Engineers, 2017). If those new vehicle trips will cause a drop in LOS below pre-established acceptable levels, then a developer can be required to provide improvements to the transportation network to accommodate the new trips and thus return to accepted LOS as a precondition of project approval.

Many local and state governments view this process as a critical means of generating needed infrastructure improvements, and its use has become ubiquitous among DOTs across the US (Schneider, Shafizadeh, \& Handy, 2015). However, reliance on this conventional approach to TIA, particularly in urban contexts, has been criticized for over-predicting (and thus over-accommodating) automobile traffic (Clifton, Currans, \& Muhs, 2015; Howell, Currans, Gehrke, Norton, \& Clifton, 2018; MillardBall, 2015; Steiner, 1998), prioritizing congestion relief at the expense of other travel modes, undermining local efforts to shift travel onto non-auto modes (de Gruyter, 2019; DeRobertis, Eells, Kott, \& Lee, 2014; Shafizadeh, Lee, Niemeier, Parker, \& Handy, 2012), and encouraging peripheral and suburban development over infill or smart-growth projects (DeRobertis et al., 2014; Schneider et al., 2015; Walters, Bochner, \& Ewing, 2013). Broad recognition of the shortcomings of conventional TIA practices as a tool for supporting contemporary demands for compact, livable projects that support walking, bicycling, and transit use is reflected in a number of recent critical reviews of the technique, including the 2015 special edition of this journal edited by Handy (2015).

Accordingly, researchers and practitioners including ITE increasingly have been working to develop new approaches to evaluating and offsetting the social and environmental costs of urban de- 
velopment projects, while simultaneously supporting multimodal-oriented development patterns and promoting non-car travel behaviors (Bochner et al., 2016; Currans, 2017; de Gruyter, 2019; Institute of Transportation Engineers, 2017). For example, Washington DC has been working to adapt TIA practices by developing context-sensitive and multimodal trip generation estimates (DDOT, 2014, 2019). California has also enacted changes, including 2018 legislation that required the use of metrics designed to capture projects' impacts on vehicle miles traveled rather than LOS for reviews required under the California Environmental Quality Act (CEQA) (Governor's Office of Planning and Research, 2019; Lee \& Handy, 2018). And in 2010 the Transportation Research Board updated the Highway Capacity Manual - the industry standard for estimating level of service - to include service standards for bicyclists and pedestrians (Elefteriadou, Dowling, \& Ryus, 2015).

However, outside of these examples there is little evidence of widespread adoption of these new approaches in the US. In a previous study, we examined the evolution of local TIA practices in the US states of Maryland, North Carolina, and Virginia. This research suggests that the conventional approach to TIA remains the default in this region. When cities did modify their TIA practices, it was typically through minor tweaks to the conventional model; substantial changes were rare even among cities with explicit multimodal-supportive transportation and land use planning goals (Combs et al., 2020). In the present study, we aim to identify factors influencing the uptake of new TIA practices among the same sample that are explicitly supportive of or oriented toward multimodal objectives. Our analysis focuses on communities' motivations and supports for multimodal oriented practices, as well as challenges they face in adopting those practices.

\section{$3 \quad$ Research methods}

\subsection{Study area}

We conducted and analyzed semi-structured interviews with key staff involved in the development review process in 36 cities and counties in North Carolina and the DC-metro areas of Virginia and Maryland. All 36 jurisdictions had been experiencing population growth over the previous decade. The sample includes 15 of the 30 most populous cities in North Carolina plus one small but rapidly expanding college town. In Maryland and Virginia, we included 20 jurisdictions ranging from largely rural counties to major metropolises. Table 1 provides indicators on population size and density and role of the staff member interviewed in each jurisdiction.

The sample contains a mixture of sprawling, automobile-dependent communities-rural counties, small towns, and major cities - and dense pre-automobile-era towns built around established transit systems such as the DC Metro. The entire study area is characterized by increasing urbanization and growing concerns over congestion, livability, and affordability.

State departments of transportation (DOTs) manage the majority of public roadways in all three states, although their approaches to TIA and the latitude they grant localities in managing TIA on or near state roadways differ, particularly with respect to multimodal transportation. In North Carolina, the state controls nearly all roadways in rural areas and small towns and a substantial portion of roadways in urbanized areas. NCDOT oversees the development approval process along and in the vicinity all state roads, and it does so in a conventional manner and in accordance with the ITE trip generation estimates. Ad hoc deviations (e.g., allowing for adjustments on trip generation estimates for mixed use projects) are allowed but not encouraged and must be approved by NCDOT engineers (NCDOT, 2015).

Virginia DOT (VDOT) also exerts strict control over projects that influence state-owned roadways, but provides an alternative trip generation method for mixed use projects and encourages the 
use of locally-derived trip generation estimates when available (VDOT, 2019). VDOT requires predevelopment ped/bike counts for projects in which substantial ped/bike trip gen is expected, and-at VDOT's discretion—allows for limited reductions in projected vehicle trip generation estimates for those projects if they also provide a high level service for pedestrians and bicycles (VDOT, 2012).

Maryland's State Highway Administration (SHA) has established prescriptive traffic impact study guidelines for projects affecting state highways. However, localities can use their own guidelines in lieu of the SHA's, provided SHA representatives feel local guidelines are sufficient for managing traffic impacts on state roads. Regardless of the guidelines followed, a state engineer or planner must be involved in pre-proposal scoping meetings and must sign off on the final mitigation plan. Like Virginia, Maryland does incorporate some multimodal objectives when practical. The state's guidelines encourage the use of local trip generation data when available, and development of alternative guidelines for transit-oriented developments is underway. SHA's traffic impact study guidelines require pedestrian and bicycle counts and projection of impacts on pedestrian and bicycle levels of service in some areas (Maryland State Highway Administration, 2016). 
Table 1. Community and interviewee characteristics

\begin{tabular}{|c|c|c|c|c|}
\hline Population $^{1}$ & Jurisdiction ID & $\begin{array}{l}\text { Population density } \\
\text { (persons } / \mathbf{k m} 2)\end{array}$ & Interviewee role & $\begin{array}{l}\text { Interviewee in } \\
\text { senior position }\end{array}$ \\
\hline \multirow[t]{5}{*}{ Large $(>500,000)$} & MD1 & $>1,500$ & Planner & $\checkmark$ \\
\hline & MD2 & 600-999 & Planner & $\checkmark$ \\
\hline & MD5 & $600-999$ & Planner & $\checkmark$ \\
\hline & MD8 & $200-599$ & Engineer & $\checkmark$ \\
\hline & $\mathrm{NC} 1$ & $1,000-1,499$ & Planner & $\checkmark$ \\
\hline \multirow[t]{5}{*}{$(250,000-500,000)$} & MD3 & $<200$ & Engineer & $\checkmark$ \\
\hline & NC2 & $1,000-1,499$ & Planner & $\checkmark$ \\
\hline & NC7 & $600-999$ & Planner + Engineer & $\checkmark$ \\
\hline & VA4 & $200-599$ & Planner & $\checkmark$ \\
\hline & VA5 & $200-599$ & Planner & \\
\hline \multirow[t]{7}{*}{ Medium $(100,000-249,999)$} & MD7 & $<200$ & Engineer & $\checkmark$ \\
\hline & NC4 & $600-999$ & Engineer & $\checkmark$ \\
\hline & NC5 & $200-599$ & Planner + Engineer & \\
\hline & $\mathrm{NC} 15$ & $600-999$ & Engineer & \\
\hline & VA1 & $>1,500$ & Planner & $\checkmark$ \\
\hline & VA2 & $>1,500$ & Engineer & \\
\hline & VA11 & $200-599$ & Planner & $\checkmark$ \\
\hline \multirow[t]{11}{*}{$(50,000-99,999)$} & MD4 & $>1,500$ & Planner & \\
\hline & MD9 & $<200$ & Engineer & \\
\hline & NC3 & $1,000-1,499$ & Engineer & $\checkmark$ \\
\hline & NC8 & 600-999 & Planner & $\checkmark$ \\
\hline & NC9 & $1,000-1,499$ & Planner + Engineer & $\checkmark$ \\
\hline & $\mathrm{NC} 12$ & $200-599$ & Engineer & $\checkmark$ \\
\hline & $\mathrm{NC13}$ & $200-599$ & Engineer & $\checkmark$ \\
\hline & NC16 & $600-999$ & Engineer & $\checkmark$ \\
\hline & VA7 & $<200$ & Planner & \\
\hline & VA9 & $<200$ & Planner & $\checkmark$ \\
\hline & VA10 & $<200$ & Planner & $\checkmark$ \\
\hline \multirow[t]{8}{*}{ Small $(<50,000)$} & MD6 & $>1,500$ & Planner & $\checkmark$ \\
\hline & NC6 & $600-999$ & Planner & $\checkmark$ \\
\hline & $\mathrm{NC} 10$ & $600-999$ & Engineer & $\checkmark$ \\
\hline & $\mathrm{NC11}$ & $600-999$ & Engineer & \\
\hline & $\mathrm{NC} 14$ & $600-999$ & Planner & $\checkmark$ \\
\hline & VA3 & $>1,500$ & Planner & $\checkmark$ \\
\hline & VA6 & $>1,500$ & Planner & \\
\hline & VA8 & $1,000-1,499$ & Planner & $\checkmark$ \\
\hline
\end{tabular}

${ }^{1}$ source: Census 2017 population estimate. 


\subsection{Data collection and analysis}

Interviews took between 30 and 45 minutes and were conducted during the summer of 2018 . The interview instrument was designed to elicit information on current TIA procedures, the extent to which relevant parties were recognizing a need for and adopting more multimodal-oriented practices and adopting, and motivations for, enablers of, and obstacles to adapting TIA practices to support more multimodal-oriented objectives. Interviews were audio recorded, transcribed, and content-analyzed using a general inductive content analysis approach. For a more detailed description of the research design, analysis methods, and characteristics of participating communities, please refer to Combs et al. (2020).

To understand the multimodal aspects of TIA practices, we asked interviewees to share both their critiques of the conventional approach to TIA, as well as their community's primary objectives in pursuing alternative practices. We extracted responses that specifically addressed multimodal issues and labeled them collectively as "multimodal-oriented motivations for TIA adaptation" ("multimodal motivations" for short). In order to identify TIA adaptations that were driven by or are likely to contribute to multimodal objectives, we asked interviewees to describe how each of the reported adaptations was applied.

In order to explore commonalities among jurisdictions and identify characteristics that might be linked to increased adoption of multimodal-supportive TIA adaptions, we plotted the number of unique multimodal TIA practices each community had adopted against the number of unique motivations expressed in support of multimodal practices (Figure 1, section 4.2). This plot enables us to sort communities into five groups, across which we compare adoption of multimodal practice changes.

\section{$4 \quad$ Findings}

Our findings are organized as follows: first, we present a summary of the multimodal-oriented motivations for TIA adaptation and the actual multimodal-oriented practice adaptations present in our 36-community sample. Based on the multimodal motivations and multimodal adaptations observed, we then develop and describe five types of communities, ranging from leading to conventional. Next, we summarize the drivers of, barriers to, and sources of information about changing TIA practices present in our study sample, overall and by community type. Finally, we discuss patterns among the drivers and barriers to adoption of multimodal practices across community type.

\subsection{Multimodal shifts in practice}

\subsubsection{Multimodal-oriented motivations for TIA adaptation}

Many interviewees stated that conventional TIA practices conflict with their communities' long-term urban planning objectives to promote more sustainable development patterns. A desire to align TIA with their planning objectives motivated many communities to change TIA practices. Motivations for changing TIA practice also included keeping pace with changing urban conditions, better alignment of development and/or traffic mitigation outcomes with community visions, support for economic development, and comportment with form-based codes were common motivations for practice adaptation. Many interviewees also expressed concerns over conventional TIA's inherent bias in favor of automobile traffic over other modes, its reliance on outdated or incorrect automobile trip generation data provided by ITE, and its failure to account for non-car impacts associated with new development or traffic mitigations. Several communities had a stated goal of improving accommodations for non-car travel modes through TIA practice adaptation. 
While not directly related to multimodality, inflexibility in TIA processes was a commonly expressed concern with likely implications for multimodal-oriented outcomes. Interviewees specifically criticized conventional TIA's exclusion of "atypical" land uses (for example, a university student life center), limitations in scope and/or focus, and inability to address the "fit" of a development project in a given context. Many interviewees hoped their adaptations would allow more flexibility in the TIA process and/or mitigation requirements. Criticism over the lack of utility of information derived from conventional TIA and the desire to move to a process that produced more valuable or actionable information about the impacts of a development project were present in several places.

\subsubsection{Practice adaptations}

Multimodal-oriented TIA adaptions varied widely across the 36 communities in our study. We identified 57 unique adaptations across the sample. We consolidated these down into six general families of change, described below.

Most multimodal-oriented adaptations fell into one of three families: accommodate non-car modes, adjust trip generation, and waive requirements. Adaptations in the accommodate non-car modes family require applicants to measure, include provisions for, or mitigate development impacts to non-car travel modes. This practice is typically imposed as an addition to a TIA, although in a few cases were integrated into the analysis.

The adjust trip generation family focuses on changes to the way the number of vehicle trips induced by a new development is estimated. These changes include using locally collected data and/or locally calibrated models and deflating the ITE handbook's trip generation estimates for proposals in areas where substantial non-car traffic is expected or desired.

Waive requirements involves allowing some sort of variance, waiver, or exception to the TIA process under specified conditions. These are often employed when the conventional TIA process would result in recommendations for mitigations that would have clear deleterious impacts on non-car modes (for example, when adding a travel or turn lane would lengthen pedestrian crossing distances).

Less common adaptations with potential multimodal implications include shifting some aspects of the TIA process into a community's planning department (shift to planning), requiring that any traffic impacts of new developments be able to be addressed by a pre-determined set of acceptable mitigations (mitigation limits), and changing the thresholds that define when congestion impacts of new development require mitigation (level of service [LOS] adjustments).

\subsection{Community typologies}

Figure 1 presents a graph of the degree to which interviewees in our 36 communities expressed multimodal-oriented motivations for changing TIA practice (vertical axis) and the number of multimodal practice changes adopted in each community (horizontal axis). Assessing communities on these axes allows us to identify groups with similar approaches and explore how approaches differ across the sample. 


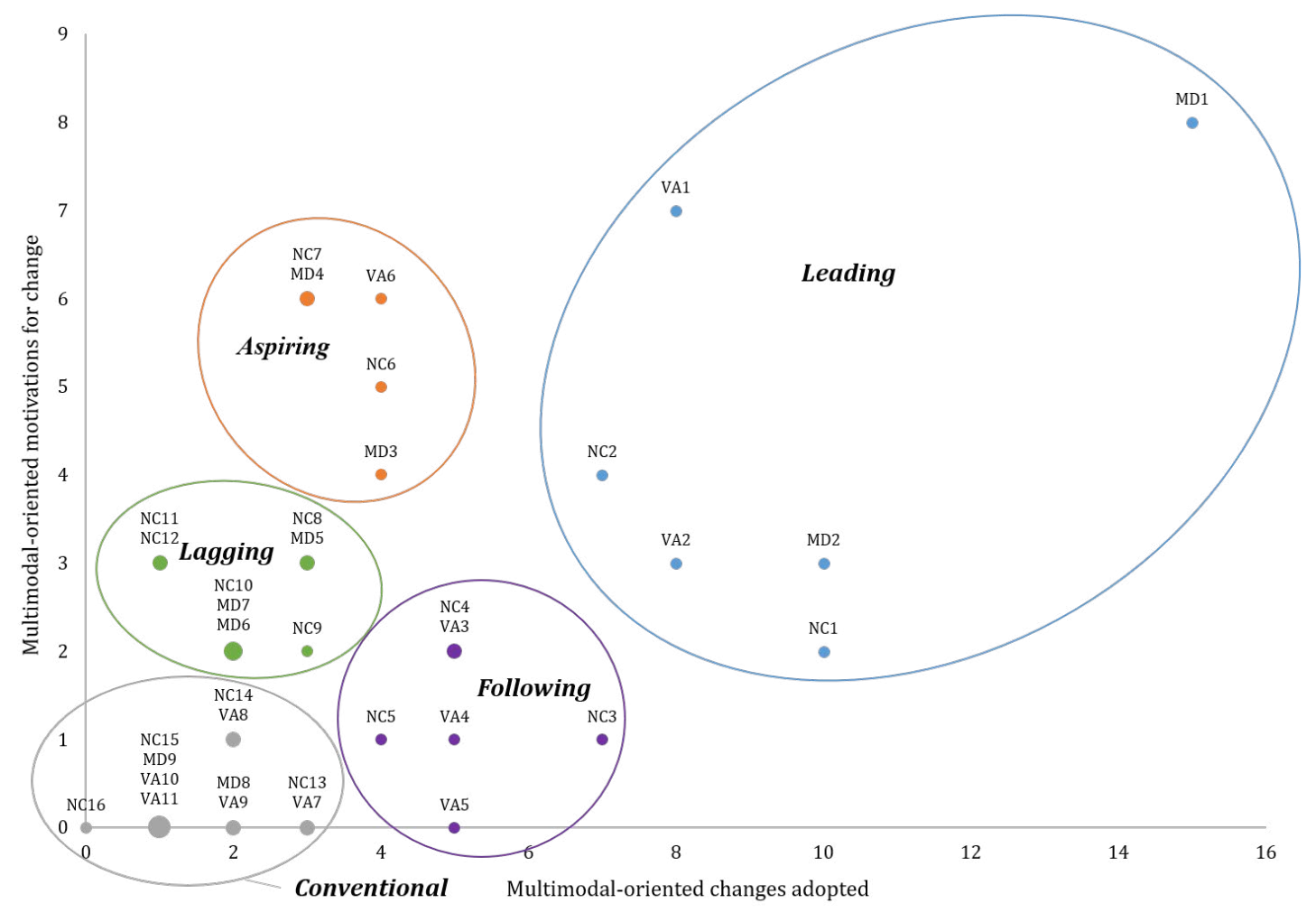

Figure 1. Number of motivations for multimodal change and multimodal practice adaptations by community

Five distinct groups of communities are apparent from Figure 1. Six communities-MD1, MD2, $\mathrm{NC} 1, \mathrm{NC} 2$, VA1, and VA2 - are clearly setting themselves apart from the rest of the sample with respect to the number of multimodal changes adopted (seven or more). For obvious reasons, we label this group of communities "leaders." The leading group includes most of the largest jurisdictions (population $>500,000)$ in our sample. All have population densities of at least 1,000 persons per $\mathrm{km}^{2}$ and either anchor or are part of a major metropolitan area. All but one of the interviewees in this group had a planning background.

Five communities show a level of motivation to change on par with or greater than the leading group, but with substantially fewer changes actually in place. This group, consisting of MD3, MD4, NC6, NC7, and VA6, we term "aspiring." The aspiring group spans the population and density ranges of our sample and includes equal numbers of planners and engineers as interviewees (NC7 provided one of each). All communities in this group are in (but are not anchors for) metropolitan regions.

The "following" group, in contrast, appears to have had slightly more success in adopting multimodal TIA practices, but lack clear motivation driving those changes. The six communities in the "following" group are NC2, NC4, NC5, VA2, VA4, and VA5. Like the aspiring group, the followers span the range in terms of population size and density and include an even balance of planners and engineers as interviewees. Unlike the two previous groups, followers are either mid-size towns (not part of a major metro area: NC3, NC4, and NC5) or suburban/bedroom communities (VA3, VA4, and VA5).

Next, we have the "lagging" group: eight communities that have expressed some interest in adopting multimodal practice (two to three motivations), but with little change to show for it (three or fewer adopted changes). This group consists of: NC8, NC9, NC10, NC11, NC12, MD5, MD6, and MD7. Most of the communities in the lagging group are smaller (fewer than 100,000 population) and less dense than in the previous three groups. Interviewees in this group included three planners, four engi- 
neers, and one planner/engineer duo. The lagging group includes a mix of mid-size towns, suburbs, and rural bedroom communities.

Finally, near the origin in Figure 1, we see a cluster of 11 communities whose practices deviate very minimally, if at all, from the conventional, automobile-oriented approach to TIA, and who express little to no interest in multimodal adaptations. These communities we label "conventional." Like the lagging group, conventional communities tend to be smaller and lower density than the rest of the sample. This group includes a grab bag of major metropolitan suburbs, stand-alone towns, and rural communities. Planners and engineers are roughly equally represented across the conventional group. Since our primary interest is understanding communities that have adopted multimodal practices, we do not discuss the conventional communities further.

Despite differences in state-level guidance on local TIA practices, our data do not provide evidence of a state effect in the degree to which communities had adopted or were motivated to adopt multimodal TIA practices.

\subsection{Motivations by community type}

Interviewees from the six leading communities shared multiple motivations for practice change; the most common being a perceived lack of utility of information derived from conventional TIA and a desire to better accommodate non-car modes. The latter motivation comports with a priori thinking that as populations demand more livable, walkable cities, local governments will need to respond by adopting policies that support those demands.

Communities in the aspiring group also expressed multiple reasons for practice adaptations. The most common motivation in this group, given in four of the five aspiring communities, was a desire to promote more sustainable or multimodal-oriented development patterns.

Following and lagging communities listed few multimodal-oriented motivations for change. When interviewees in these groups did report motivations, they tended to focus not on multimodalism, but on improving transparency, flexibility, or efficiency in the TIA process, providing more useful information, or reducing the burden of TIA on developers.

\subsection{Adaptations by community type}

Accommodate non-car modes, adjust trip generation, and waive requirements were the most common types of multimodal adaptations, and were present in all four community groups. Shift to planning, mitigation limits, and LOS adjustments were present mainly among the leaders, with just sporadic adoptions among the following, aspiring, and lagging communities. Table 2 shows the average number of distinct multimodal adaptations in each family for each type of community. 
Table 2. Average number of multimodal-oriented practice changes (by change family) adopted by communities (by community type)

\begin{tabular}{|cccccccc|}
\hline \multirow{2}{*}{$\begin{array}{c}\text { Community } \\
\text { type }\end{array}$} & $\begin{array}{c}\text { Accommodate } \\
\text { non-auto }\end{array}$ & $\begin{array}{c}\text { Adjust trip } \\
\text { generation }\end{array}$ & $\begin{array}{c}\text { Waive } \\
\text { requirements }\end{array}$ & $\begin{array}{c}\text { Shift to } \\
\text { planning }\end{array}$ & $\begin{array}{c}\text { Limit } \\
\text { mitigations }\end{array}$ & $\begin{array}{c}\text { Adjust } \\
\text { LOS }\end{array}$ & $\begin{array}{c}\text { Mean, all } \\
\text { families }\end{array}$ \\
\hline Leading & 2.2 & 1.7 & 1.8 & 1.2 & 0.8 & 0.5 & 8.2 \\
Following & 1.2 & 1.8 & 1.2 & 0.5 & 0.5 & 0.0 & 5.2 \\
Aspiring & 1.4 & 0.8 & 0.4 & 0.4 & 0.2 & 0.2 & 3.4 \\
Lagging & 0.5 & 0.6 & 0.6 & 0.0 & 0.0 & 0.3 & 2.0 \\
\hline Total & 1.3 & 1.2 & 1.0 & 0.5 & 0.4 & 0.2 & \\
\hline
\end{tabular}

The most common form of adaptation among leading communities was accommodate non-car modes, followed by waive requirements and adjust trip generation. All six leaders have adopted at least one adaptation in each of these families save one (no adjust trip generation adaptation in NC2). Each leading community has also incorporated at least one of the three less common adaptation families (shift to planning, limit mitigations, and adjust LOS, though only MD1 and MD2 had adopted adaptations from each family). Leading communities appear to be taking a multipronged approach to TIA practice adaptation: of the six families of adaptations identified (i.e., accommodate non-car, trip generation, waivers, planning, mitigation limits, and LOS adjustments), at least four had been adopted in each of the leading communities.

Most adaptions among aspiring communities were restricted to accommodate non-car modes and adjust trip generation (1.4 and 0.8 adoptions per community, respectively); each of these adaptation families were present in four of the five aspiring communities. No aspiring community had taken up more than one additional adaptation family.

Among the followers, adjustments to trip generation was the most common adaptation (1.8 average adoptions per community), followed by accommodate non-car modes and waive requirements (each with 1.2 adoptions per community). Shift to planning and limit mitigations were uncommon among followers, and no follower had incorporated any adjustments to LOS adaptations.

As expected, communities in the lagging group had few adaptations in use. Adjust trip generation and waive requirements were the most common forms of adaptation in this group (each present in four of the seven lagging communities, 0.6 adaptions per community on average). Shift to planning and limit mitigations were absent from the lagging group entirely.

\subsection{Factors shaping adoption of new practices}

Previous research suggests communities' appetite for and success in adopting new practices are shaped by at least three kinds of change factors: catalysts for action, barriers to action, and sources of information about alternative practices (Brody, Carrasco, \& Highfield, 2006; Combs et al., 2020; De Vries, Bekkers, \& Tummers, 2016; LaJeunesse, Heiny, Evenson, Fiedler, \& Cooper, 2018). We asked interviewees to describe the specific catalyst, barrier, and information source change factors their communities' practices are influenced by, and the extent to which these factors shaped their communities' efforts to adopt more multimodal-oriented TIA practices. We summarize the predominant change factors by community type in order to identify characteristics of communities with success in making progress toward multimodal TIA practices below (additional detail on the change factors are provided in Combs et al., 2020).

Catalysts are the people and/or events that instigate change. Interviewees identified catalysts in $64 \%$ of our communities, including local government staff, elected officials, appointed committees, special interest groups, and the general public, as well as special events such as scheduled regulatory updates 
and controversial development projects.

Barriers to the adoption of new practices-internal or external forces or obstacles communities must dismantle or work around before change can take place-were discussed in just over half the communities studied. Barriers included a lack of data or technical supports, state regulations, and pushback from the public, elected officials, or special interest groups.

Finally, communities need a way to identify or learn about alternative practices. Interviewees in all but three communities identified at least one source of information about new approaches to TIA. Frequent information sources included peer or neighboring communities, consultants, and professional development activities.

Table 3 shows the prevalence of each of these change factors within each type of community.

Table 3. Number and percentage of communities reporting change factors, by community type

\begin{tabular}{|c|c|c|c|c|c|c|c|c|}
\hline & \multicolumn{2}{|c|}{ Leading } & \multicolumn{2}{|c|}{ Aspiring } & \multicolumn{2}{|c|}{ Following } & \multicolumn{2}{|c|}{ Lagging } \\
\hline & $\#$ & $\%$ & $\#$ & $\%$ & $\#$ & $\%$ & $\#$ & $\%$ \\
\hline \multicolumn{9}{|l|}{ Catalysts for change } \\
\hline \multicolumn{9}{|l|}{ People } \\
\hline Staff & 4 & 67 & 4 & 80 & 1 & 17 & 3 & 38 \\
\hline Elected officials & 3 & 50 & 2 & 40 & 1 & 17 & 2 & 25 \\
\hline Public & & & 2 & 40 & 1 & 17 & 2 & 25 \\
\hline Appointed officials & 1 & 17 & & & & & 2 & 25 \\
\hline Developers & & & & & 1 & 17 & & \\
\hline \multicolumn{9}{|l|}{ Events } \\
\hline Scheduled regulatory update & 1 & 17 & 2 & 40 & 1 & 17 & & \\
\hline Specific project/proposal & 1 & 17 & & & 1 & 17 & 2 & 25 \\
\hline State action/policy & & & & & 1 & 17 & & \\
\hline \multicolumn{9}{|l|}{ Barriers to change } \\
\hline Developer opposition & 2 & 33 & 2 & 40 & & & 2 & 25 \\
\hline Lack of guidance & 1 & 17 & 3 & 60 & 1 & 17 & 1 & 13 \\
\hline State/DOT opposition & 1 & 17 & 2 & 40 & & & 1 & 13 \\
\hline Fear of congestion & 3 & 50 & 2 & 40 & & & & \\
\hline Public opposition & 3 & 50 & 1 & 20 & & & & \\
\hline Inertia & 3 & 50 & & & & & 1 & 13 \\
\hline Politics/leadership & 2 & 33 & 1 & 20 & & & 1 & 13 \\
\hline Internal conflict & 1 & 17 & 1 & 20 & & & & \\
\hline Complexity & & & & & 1 & 17 & 1 & 13 \\
\hline Fear of legal challenges & 1 & 17 & & & & & 1 & 13 \\
\hline \multicolumn{9}{|l|}{ Information sources } \\
\hline Neighboring or peer communities & 2 & 33 & 3 & 60 & 1 & 17 & 4 & 50 \\
\hline Consultants & 4 & 67 & 2 & 40 & 1 & 17 & 3 & 38 \\
\hline Professional development & 3 & 50 & 2 & 40 & 3 & 50 & & \\
\hline Internal staff knowledge & 3 & 50 & 1 & 20 & 2 & 33 & & \\
\hline State DOT & & & 1 & 20 & 1 & 17 & 2 & 25 \\
\hline ITE handbook & 1 & 17 & 1 & 20 & & & & \\
\hline Public engagement/public input & 2 & 33 & 0 & & & & & \\
\hline Internet searches & & & & & 1 & 17 & 1 & 13 \\
\hline
\end{tabular}




\subsection{Change factors by community type}

In the leading group, TIA practice adaptation has largely been driven by local staff; elected officials were also listed as catalysts of change in two of the six leading communities. These communities rely on multiple sources of information in their efforts to identify and adopt new TIA practices; each interviewee listed at least two different sources of information. The top sources of information in this group are consultants, professional development (conferences, continuing education opportunities, and literature), and internal staff knowledge (i.e., hiring of new staffers based in part on their ability to introduce new concepts and ideas about TIA).

Interviewees in the leading group were quick to point out barriers or obstacles to adopting change, and reported almost as many barriers to change (21 barriers expressed among the six leading communities) as the three other non-conventional groups (i.e., following, aspiring, and lagging) combined (24 barriers). Leaders also reported a diverse range of barriers, including public opposition, political challenges, and inertia, i.e., a general sense that it's just too hard to change entrenched practices. Fear of congestion and opposition from the development community were also mentioned.

Like the leaders, aspiring communities' changes were driven in nearly every case by staff. Elected officials and the public were the second-most common catalysts among this group; interviewees in one city (NC6) listed all three (staff, elected officials, and the public). Aspiring communities also tended to seek information about alternative TIA practices from a variety of sources. The most common information source for aspiring communities was neighboring and peer communities (three of five communities), followed by professional development (two of five) and consultants (two of five).

Lack of guidance was the top barrier to change in the aspiring group. While nearly all communities in the leading group felt like they were up against multiple barriers to change, only two of the five in this group reported more than one barrier.

Followers reported very few catalysts for change. Only one following community listed more than one catalyst (NC3; staff and elected officials), and no particular catalyst was provided by more than one interviewee. Nevertheless, interviewees in the following group did report consulting a variety of sources of information on alternatives to conventional TIA. The primary source of information is professional development (listed in 3 sites), followed by internal staff knowledge. Only two of six followers reported any barriers to change (one reported lack of guidance, the other complexity).

Interviewees in the lagging group showed some similarities with the aspiring group with respect to catalysts for change (staff being the most common catalyst, followed by elected officials and the public). The primary sources of information on TIA change were neighboring communities (four of eight) and consultants (three). Like the following group, lagging communities reported unsurprisingly few barriers to change save one-MD6 - which expressed a laundry list of barriers to change: resistance from developers, lack of technical guidance/support, inertia, and fear of legal challenges to new practices.

Figure 2 allows for a quick comparison of the dominant motivations, drivers, and barriers to change across community types. 


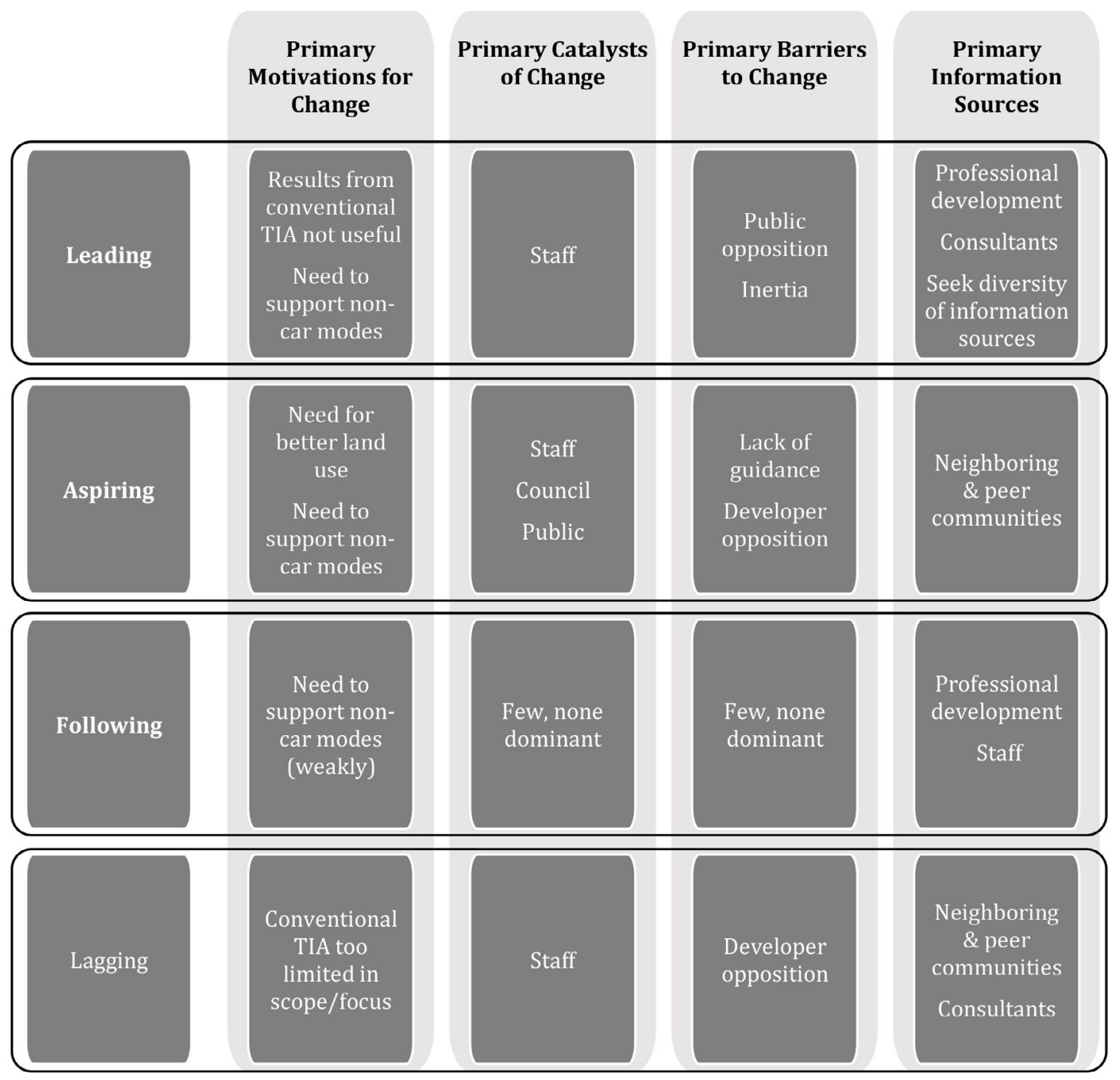

Figure 2. Summary of leading change factors in each community type

\section{Discussion}

The desire to create environments that better support non-car travel emerged as a common factor motivating communities' efforts to adopt more multimodal oriented TIA practices, showing up as a motivation for practice change in multiple communities in our leading, aspiring, and following groups.

Staff play a critical role in driving the adoption of multimodal TIA practices, at least among all but the following group. Staff was the most commonly discussed catalyst of multimodal-oriented change in all by the following group and was listed in the majority of both leading and aspiring groups. However, in nearly every case, interviewees also listed at least one additional catalyst of change, suggesting that while staff appears to be an important catalyst of change, it may not be sufficient in most settings. 


\subsection{How do communities differ?}

We note three important differences among our community groups' discussions of change factors. These differences include information sources, barriers to change, and the role of the public.

First, the two groups of communities with the fewest practice adaptations in place-the aspiring and lagging groups-show a different preference for information sources compared to communities that have had more success in adopting multimodal supportive practices (leaders and followers). While leading and following communities seek information from a variety of sources (with dominant sources being professional development and consultants), aspiring and lagging communities seek a narrower range of information sources and rely much more heavily on guidance from neighboring and peer communities. This finding suggests that seeking information from a range of sources may be an important differentiator between motivated communities with a track record of successful multimodal practice adoption (i.e., leading communities) and those without that success (i.e., aspiring communities).

Next, interviewees reported a wide range of barriers to adoption of multimodal TIA practice adaptions. The most common barriers reported were developer opposition and lack of guidance, data, or technical support, although each were present in fewer than $25 \%$ of our sample. Recognition of barriers to change seems to be positively linked to motivation for change: communities in the following and lagging groups rarely provided any barriers to change; most aspiring communities reported at least one barrier, and most leaders reported multiple barriers to adopting multimodal supportive TIA practices.

The types of barriers faced differed between leading and aspiring communities: lack of guidance or technical support was the number one barrier reported among aspiring communities but was an apparent non-factor in the leading group. Among leaders, the top barriers to change included both public opposition (including the fear that new practices would exacerbate congestion) and inertia.

Finally, we see an interesting difference in how communities view the role of the public in efforts to adopt multimodal supportive TIA practices. The public was the third-most frequently listed agent of change, and was present in aspiring, following, and lagging communities. Among leaders, the public was also listed frequently; never as a catalyst for change though, but as a barrier. This conflicting view of the role of the public in the change process is another striking difference between the leading and aspiring groups and raises some interesting questions for future investigations. For example, is a change process dependent upon members of the public to drive it inherently less likely to succeed than one driven by staff or elected officials? Or, is the public more likely to present as a barrier when changes are taking place? These questions extend well beyond TIA and have broad implications for planning and governance as cities are increasingly faced with needs to adapt to rapidly changing conditions.

\subsection{Implications for scholarship and practice}

These commonalities and differences highlight an important takeaway for practice: the importance of the role of information and the ways communities go about acquiring information. One of the most common barriers to change we identified is lack of guidance, technical knowledge, or support tools. We view this as a positive finding because of its actionable implications: more accessible, useful tools and guidance may be the key for many communities to unlocking practices that better align with their desired outcomes. Additionally, communities with strong multimodal inclinations (leading and aspiring) lean heavily on literature and professional development activities in order to learn about new ways to manage traffic impacts; this provides obvious pathways for dissemination of new tools and guidance from research to practice. However, these pathways are less likely to be productive among lagging communities, which rely more on peer communities and consultants for information about new practices. Thus, if in-roads are to be made at this end of the spectrum, it must be via professional networks and 
consultant-focused outreach efforts rather than through typical research dissemination channels.

Finally, it's worth noting that aside from accommodations for non-car modes, there were no clear "favorites" among the types of practice adaptations in our study communities. As a result, we are unable to point to the emergence of any new "best practices" for multimodal supportive TIA. However, the wide range of practices in place, particularly among our leading communities, leads us to wonder whether a tailored and multi-pronged approach to practice change is, on its own, a best practice, or simply a reflection of need for experimentation among communities at the leading edge of practice change. The latter idea is supported by a large body of research on public sector policy innovation, which suggests that the absence of established best practices may lead more proactive communities to experiment through the invention of new procedures and policies. Eventually, that experimentation may lead to a knowledge base sufficient for the field to identify and disseminate a more well-defined set of best practices (Boushey, 2012; Jun \& Weare, 2011; Nehme, Pérez, Ranjit, Amick, \& Kohl, 2016; Shipan \& Volden, 2008, 2012; Walker, Avellaneda, \& Berry, 2011). If this is the case, it may be a clue that more research is needed into precisely what sorts of TIA practice are most likely to support the multimodal outcomes desired by so many of the communities in our study.

We may also be witnessing a shift at the leading edge toward context-sensitivity as a best TIA practice. That is to say, leading communities may be recognizing that a once-size-fits-all approach to TIA is inadequate, and are thus developing new ideas for best practices that are tailored to their unique situations rather than simply adopting approaches that have worked elsewhere. Either way, efforts from the research community to develop and disseminate new tools and techniques for evaluating and mitigating the impacts of new developments will likely go a long way toward enabling communities to eliminate mismatches between established practices and desired outcomes.

\subsection{Questions for further research}

This research is exploratory, thus highlighting questions that need to be studied. We are particularly curious about the following group, which, despite showing little inclination to adopt multimodal TIA practices and having few identifiable catalysts for change, have nevertheless been able to adopt a substantial number of multimodal-supportive TIA practices. We are intrigued by the apparent ability of communities in the following group to adopt multimodal practice changes despite a lack of both motivations and catalysts for multimodal change. Why these communities are changing absent any apparent drivers of change, in contrast to the clear ambition but lack of progress shown by their aspiring peers, is curious. Perhaps the multimodal practice changes reported by our interviewees occurred so long ago (as was the case in at least one of the followers) that the supportive structures that drove those changes are no longer present. It may also be that the multimodal-supportive changes taking place in this group were convenient side-effects of larger practice changes driven by non-multimodal motivations such as flexibility or efficiency. Finally, we cannot ignore the possibility that, in some communities, our interviewees might have been unsupportive of the changes taking place, and therefore less likely to view and report the forces behind those changes as positives.

Perhaps this can be explained in part by the near complete lack of barriers expressed among followers: have those communities have simply pursued the low hanging fruit among the suite of TIA practice changes available to them, thus neither needing a driving force nor encountering barriers that my hinder more innovative changes?

As has been noted elsewhere (e.g., Manville, 2017), we recognize that the role and status of the interviewee, the community's institutional characteristics (e.g., organizational structure, role, background, and status of the interviewee), and socio-spatial characteristics (e.g., size, prevailing travel patterns, urbanicity, development context) likely also influence practices and appetite for change. In our sample 
of 36 communities, we do not note substantial differences in communities' population size, density, or interviewees' professional backgrounds across the community types outside of the extremes (leading communities tend to be larger, denser, and more likely to be represented by planners than the rest of the sample, while conventional communities are, in general, smaller and less dense than the rest of the sample). However, we suspect stronger differences may emerge with a larger sample size. We are hopeful that future research efforts are able to assess the influence of institutional and socio-spatial characteristics and development context on the evolution of planning and engineering practices including TIA.

\section{Conclusion}

In this study, we evaluated the extent to which local governments are pursuing multimodal oriented TIA practices, and to identify reasons why they might or might not be successful in adopting those practices. We rely on content analysis of transcripts from structured interviews with local government staff in 36 cities and counties in MD, VA, and NC involved in their agencies' development review process as our data source.

We found that both the motivation to adopt multimodal oriented TIA practices and actual adoption of such practices vary widely even within this geographically restricted region. We identified five types of communities: leaders (which had both relatively good success in adopting multimodal oriented TIA practices and showed relatively high motivation to do so), aspiring communities (which showed high motivation for adopting new practices but relatively low adoption rates), followers (low motivation, relatively high adoption, although not as high as the leaders), lagging communities (low motivation, low adoption), and conventional communities (no motivation to change, virtually no deviation from conventional TIA practices).

Our analysis uncovered a number of commonalities and differences across these groups with respect to potential drivers of and barriers to adoption of multimodal oriented TIA practices. One common theme was the importance of having staff play a role in pushing for multimodal oriented practices, however we also note that staff alone does not appear to be sufficient to drive change.

The research highlights the importance of information and guidance and identifies channels though which that information on new approaches (and how to implement them) might effectively be disseminated to increase the potential for change across community types.

\section{Acknowledgments}

This research was made possible through support from Southeastern Transportation Research, Innovation, Development, and Education (STRIDE) Center (USDOT Grant 69A3551747104). 


\section{References}

Bochner, B. S., Currans, K. M., Dock, S. P., Clifton, K. J., Gibson, P. A., ... \& Tierney, L. F. (2016). Advances in urban trip generation estimation. ITE Journal, 86(7), 17-19.

Boushey, G. (2012). Punctuated equilibrium theory and the diffusion of innovations. Policy Studies Journal, 40(1), 127-146.

Brody, S. D., Carrasco, V., \& Highfield, W. E. (2006). Measuring the adoption of local sprawl: Reduction planning policies in Florida. Journal of Planning Education and Research, 25(3), 294-310. https://doi.org/10.1177/0739456X05280546

Clifton, K. J., Currans, K. M., \& Muhs, C. D. (2015). Adjusting ITE's trip generation handbook for urban context. Journal of Transport and Land Use, 8(1), 5-29.

Combs, T. S., McDonald, N. C., \& Leimenstoll, W. (2020). Evolution in local traffic impact assessment practices. Journal of Planning Education and Research. https://doi.org/10.1177/0739456X20908928

Currans, K. M. (2017). Issues in trip generation methods for transportation impact estimation of land use development: A review and discussion of the state-of-the-art approaches. Journal of Planning Literature, 32(4), 335-345. https://doi.org/10.1177/0885412217706505

DDOT. (2014). Trip generation data collection in urban areas. District of Columbia Department of Transportation. Retrieved from https:/umjp9n8g2j2ft5j5637up17u-wpengine.netdna-ssl.com/wpcontent/uploads/2014/04/2014-01_Urban-Trip-Generation-Final-Report.pdf

DDOT. (2019). Guidance for comprehensive transportation review (p. 143). Washington, DC: District of Columbia Department of Transportation.

de Gruyter, C. (2019). Multimodal trip generation from land use developments: International synthesis and future directions. Transportation Research Record, 2673, 136-152. https://doi. org/10.1177/0361198119833967

De Vries, H., Bekkers, V., \& Tummers, L. (2016). Innovation in the public sector: A systematic review and future research agenda. Public Administration, 94(1), 146-166. https://doi.org/10.1111/ padm.12209

DeRobertis, M., Eells, J., Kott, J., \& Lee, R. W. (2014). Changing the paradigm of traffic impact studies: How typical traffic studies inhibit sustainable transportation. ITE Journal, 84(5), 30-35.

Elefteriadou, L., Dowling, R. G., \& Ryus, P. (2015). Exploring multimodal analysis in the highway capacity manual 2010. ITE Journal, 85(2), 27-31.

Governor's Office of Planning and Research. (2019). Transportation impacts (SB 743). Retrieved from http://opr.ca.gov/ceqa/updates/sb-743/

Handy, S. (2015). Trip generation: Introduction to the special section. Journal of Transport and Land Use, $8(1), 1-4$.

Howell, A., Currans, K., Gehrke, S., Norton, G., \& Clifton, K. (2018). Transportation impacts of affordable housing: Informing development review with travel behavior analysis. Journal of Transport and Land Use, 11(1), 103-118. https://doi.org/10.5198/jtlu.2018.1129

Institute of Transportation Engineers. (2017). Trip generation manual (10th ed.). Washington, DC: Institute of Transportation Engineers. https://www.ite.org/page-for-layout/

Jun, K.-N., \& Weare, C. (2011). Institutional motivations in the adoption of innovations: The case of e-government. Journal of Public Administration Research and Theory: J-PART, 21(3), 495-519.

LaJeunesse, S., Heiny, S., Evenson, K. R., Fiedler, L. M., \& Cooper, J. F. (2018). Diffusing innovative road safety practice: A social network approach to identifying opinion leading U.S. cities. Traffic Injury Prevention, 19(8), 832-837. https://doi.org/10.1080/15389588.2018.1527031

Lee, A. E., \& Handy, S. L. (2018). Leaving level-of-service behind: The implications of a shift to 
VMT impact metrics. Research in Transportation Business \& Management, 29, 14-25. https://doi. org/10.1016/j.rtbm.2018.02.003

Manville, M. (2017). Automatic street widening: Evidence from a highway dedication law. Journal of Transport and Land Use, 10(1), 375-393. https://doi.org/10.5198/jtlu.2016.834

Maryland State Highway Administration. (2016). Draft guidelines for traffic impact reports/studies. Retrieved from https://www.roads.maryland.gov/mdotsha/pages/Index.aspx?PageId=393

Millard-Ball, A. (2015). Phantom trips: Overestimating the traffic impacts of new development. Journal of Transport and Land Use, 8(1), 31-49.

NCDOT. (2015). NCDOT congestion management capacity analysis guidelines [Instructions]. Retrieved from https://connect.ncdot.gov/resources/safety/Congestion\%20Mngmt\%20and\%20Signing/Congestion\%20Management/Capacity\%20Analysis\%20Guidelines.pdf

Nehme, E. K., Pérez, A., Ranjit, N., Amick, B. C., \& Kohl, H. W. (2016). Behavioral theory and transportation cycling research: Application of diffusion of innovations. Journal of Transport \& Health, 3(3), 346-356. https://doi.org/10.1016/j.jth.2016.05.127

Schneider, R. J., Shafizadeh, K., \& Handy, S. L. (2015). Method to adjust Institute of Transportation Engineers vehicle trip-generation estimates in smart-growth areas. Journal of Transport and Land Use, $8(1), 69-83$.

Shafizadeh, K., Lee, R., Niemeier, D., Parker, T., \& Handy, S. (2012). Evaluation of operation and accuracy of available smart growth trip generation methodologies for use in California. Transportation Research Record, 2307(1), 120-131. https://doi.org/10.3141/2307-13

Shipan, C. R., \& Volden, C. (2008). The mechanisms of policy diffusion. American Journal of Political Science, 52(4), 840-857. https://doi.org/10.1111/j.1540-5907.2008.00346.x

Steiner, R. L. (1998). Trip generation and parking requirements in traditional shopping districts. Transportation Research Record: Journal of the Transportation Research Board, 1617, 28-37.

VDOT. (2012). Traffic impact analysis regulations (24VAC30-155). Retrieved from https:// www.vdot.virginia.gov/projects/resources/chapter527/Traffic_Impact_Analysis_ Regulations_24VAC30-155_1.2012.pdf

VDOT. (2019, October 18). Traffic impact analysis regulations. Retrieved from https://www.vdot.virginia.gov/info/traffic_impact_analysis_regulations.asp

Walker, R. M., Avellaneda, C. N., \& Berry, F. S. (2011). Exploring the diffusion of innovation among high and low innovative localities: A test of the Berry and Berry model. Public Management Review, 13(1), 95-125. https://doi.org/10.1080/14719037.2010.501616

Walters, J., Bochner, B., \& Ewing, R. (2013). Getting trip generation right. In Eliminating the bias against mixed use development. Chicago: American Planning Association (APA). 